\title{
Vorschau auf die folgenden Hefte
}

Heft 103: Mediengeschichte

Heft 104: Zweitspracherwerb

Heft 105: Hemoriales Denken

\section{Bezugsbedingungen}

Die »Zeitschrift für Literaturwissenschaft und Linguistik (LiLi)« erscheint jährlich in 4 Heften. Das Einzelheft kostet DM 28.-/öS 205.-/sFr 28.-; der Abonnementpreis beträgt je Jahrgang DM 88.-/öS 643.-/sFr 83.-, das Jahresabonnement für Studierende beträgt DM 48.-/ öS 351.-/sFr 46.- gegen Studienbescheinigung (Preise jeweils zuzüglich Versandkosten). Die Bezugspreise enthalten die gesetzliche Mehrwertsteuer. Abbestellungen sind spätestens zum 30. September des laufenden Jahres für den folgenden Jahrgang vorzunehmen.

Bestellungen nimmt jede Buchhandlung oder der Verlag entgegen.

Anzeigenannahme: Verlag J. B. Metzler, Postfach 103241, D-70028 Stuttgart, Tel. 0711/2194-0. Es gilt zur Zeit der Anzeigentarif Nr. 1 vom 1.1.1995.

Die Hefte 1-96 der »Zeitschrift für Literaturwissenschaft und Linguistik (LiLi)« sind im Verlag Vandenhoeck \& Ruprecht, Göttingen, erschienen und noch lieferbar.

Ebenfalls noch lieferbar sind 16 Beihefte zu LiLi. Bestellungen der Hefte 1-96 sowie der Beihefte sind zu richten an: Vandenhoeck \& Ruprecht, Theaterstraße 13, D-37073 Göttingen.

\section{Impressum}

(C) Verlag: J. B. Metzlersche Verlagsbuchhandlung und Carl Ernst Poeschel Verlag GmbH, D-70182 Stuttgart, Werastraße 21-23, Telefon 0711/2194-0

Die in der Zeitschrift veröffentlichten Beiträge sind urheberrechtlich geschützt. Alle Rechte, insbesondere das der Übersetzung in fremde Sprachen, vorbehalten. Kein Teil dieser Zeitschrift darf ohne schriftliche Genehmigung des Verlages in irgendeiner Form - durch Fotokopie, Mikrofilm oder andere Verfahren - reproduziert oder in eine von Maschinen, insbesondere von Datenverarbeitungsanlagen verwendbare Sprache übertragen werden. Auch die Rechte der Wiedergabe durch Vortrag, Funk- und Fernsehsendung, im Magnettonverfahren oder auf ähnlichem Wege bleiben vorbehalten.

Fotokopien für den persönlichen und sonstigen eigenen Gebrauch dürfen nur von einzelnen Beiträgen oder Teilen daraus als Einzelkopien hergestellt werden.

Satz: Schäfer DHM Digital GmbH, Stuttgart-Vaihingen

Druck und Bindung: Franz Spiegel Buch GmbH, Ulm

Printed in Germany

Gedruckt auf säurefreiem, alterungsbeständigem Papier.

ISSN 0049-8653

Beilagenhinweis:

Einem Teil dieser Auflage liegen Prospekte folgender Verlage bei: J. B. Metzler, Stuttgart. 